\title{
The Role of Family in Youth's Moral Behavioral Development in Bangladesh: A Socio-economic Analysis at Dhaka City
}

\author{
Muhammad Rabi Ullah \\ Assistant Professor \\ Department of Economics \\ Bangabandhu Sheikh Mujibur Rahman Science and Technology University (BSMRSTU) \\ Gopalganj-8100, Dhaka, Bangladesh \\ Abul Kalam* \\ Assistant Professor \\ Department of Sociology \\ Bangabandhu Sheikh Mujibur Rahman Science and Technology University (BSMRSTU) \\ Gopalganj-8100, Dhaka, Bangladesh \\ Mohammad Abul Khair \\ Ph.D. Research Fellow \\ Department of Anthropology, Jahangirnagar University, Dhaka, Bangladesh
}

\begin{abstract}
This study examines the youth's moral behavior role of family inspiration in Bangladesh. Most young people grow up with various problems, but some parents may want or need additional help to support their children, particularly in coping with issues that can become exacerbated during these teenage years. Parent-adolescent turmoil was supposed to be a normal occurrence triggered, in part, by raging hormones, dramatic physiological changes, re-emerging sexual impulses, and rapidly changing social expectations for the young. These research major findings are the majority of youths have lack self-confidence; modern technology affects the aggressive moral behavior of youths. Behavioral pattern and corrupt leaders and social system influence of youth's illegal and anti-social activities. Low socioeconomic status increases the high rate of attempted suicides, smoking, and drinking. It can also lead to a high level of emotional behavior including anxiety, depression, mental disorder, aggression, and antagonism of youth's moral behavior.
\end{abstract}

Keywords: Moral behavior, Socio-economic status, Adolescents, parent's child relationships, peer group.

DOI: $10.7176 / \mathrm{JLPG} / 117-03$

Publication date: January $31^{\text {st }} 2022$

\section{Introduction}

The role of the family in the influence of youth's moral behavior has been a prominent issue in Bangladesh, especially in Dhaka City. In the formation of children's morals, no outside influence is greater than that of the family. Through punishment, reinforcement and both direct and indirect teaching families instill morals in children and help them to develop beliefs that reflect the values of their culture. A family contribution to children's moral development is broad there are particular ways in which morals are most effectively conveyed and learned by youths Fairness, Justice, Social roles Personal Balance. Different societies have their own moral values which are considered normal ideal and morally acceptable. Hence the conduct of the people in a society is regulated and controlled by their moral values (Anasi, 2010). Within the context of education, therefore, the public holds the schools and teachers more accountable for students learning and behavior (Omede and Odiba, 2010). According to (Ajiboye, Atere, and Olunfunmi 2012), the United Nations puts the age of the youths between fifteen and twenty-four years. In Bangladesh government determined the age of youths from 13 to 19 years old. Psychologically, it refers to the extent of time in between childhood transform to adulthood. (Alfrey 2010), argued that youths are referred to as those people who possess certain distinct physical characteristics which include: Ability to think fast, the ability to display much energy towards the actualization of goals, assertive and resistant personality, and the ability to change a state of art. According to (Haidt 2012), at the broadest level as interconnecting sets of values, virtue, norms, practice, logical mechanisms that work together to defeat or regulate self-interest and make cooperative societies possible. In a variation of modern societies for example youths currently feel a heightened empathy with the digital age (Bennett and Manton 2010). The current revolution in technology known as the Information age or age of technology similarly is insistent the older person who is unwilling to use a computer may even accept a basic mobile telephone once considered a glamorous accessory (Cockelbergh, 2012), with the growth of technologies as the internet, computers, and television youths are becoming more dislocated from society (Griswold 2012), most youths prefer watching television and playing computer games to those moral movies that positively position them for life challenges. 


\subsection{Objectives of the Study}

The main objective of the study is to reveal factors that affect youth's moral behavior in youth at Dhaka City. The specific objectives are;

- To examine how the socio-economic background affects the influence of moral behaviors in youths within families in Dhaka both city corporations.

- To ascertain how mass media \& modern technology influence the moral behavior of youths within families in Dhaka both city corporations.

- To find out how the social and family environmental factors affect on moral behaviors of youth's psychology within the families in Dhaka both city corporations.

- To discover how peer groups influence and role model effect of moral behavior of youths within the families in Dhaka both city corporations.

\section{2 .Research Question:}

The following research questions are formulated to conduct the study:

- How does the socio-economic background affect the influence of moral behaviors in youths within families in Dhaka both city corporations?

- How do mass media and modern technology influence moral behavior in youths within the families in Dhaka both city corporations?

- How does the social and family environmental factor effect on moral behaviors of youth's psychology within the families in Dhaka both city corporations?

- How do peer groups influence and role model the effect of moral behavior of youths within the families in Dhaka both city corporations?

\subsection{Research Hypothesis:}

The null hypothesis was tested at a 0.05 level of significance;

Ho1: There is no significant difference between housewife and service holder urban families on how sociopsychological factors affect the moral behavior in youths within the families.

Ho2: There is no significant difference between males and females on peer group influence of moral behaviors in youths.

\section{Review of Literature:}

Morality and moral development are sometimes defined in terms of objective norms and established standards of behaviors. Morality often provides the basic formation for personality education programs, where a set of virtues such as sincerity, sympathy, courage, the strength of mind are recognized and encouraged. (Lawrence Kohlberg 1984), an internationally recognized researcher and expert in the field of moral development used the term a bag of virtues in discussing the restrictions of this conventional framework. A recent book by (David Callahan the Cheating Culture 2004), presents a volume of research data on the selfish nature of our culture today and people's willingness to do wrong to acquire in advance. Sometimes family breakdowns and re-marriage raising a child in a single-parent family is a regular experience. If the families can live in agreement raise children together and celebrate togetherness, they can be called hodgepodge families (Wiencelewska 2016). Nowadays more and more children are being brought up in families with one non-biological parent or they are encountering various forms of the family structure created by an enduring parent or a weekend parent structure (Kwak 2005). Family relationships created in such a way to have an impact on the youth constitute its image of the world, nature its classification of values, attitudes, and beliefs.

As positive moral characteristics do not appear spontaneously (Berkowitch \& Grych, 1998), addressing our cultural moral crisis will take the obligation and participation of many fundamentals of society, including early childhood education. Adolescence is the foundation for adulthood. Peers provide added role-taking opportunities and expose adolescents to novel moral behaviors (Hart, Atkins, Markey, \&Youniss, 2004; Hart \& Atkins 2002). Kohlberg and others argued that moral development in a more developmental and constructivist perspective believes that goodness is developed from the inside of an individual rather than being imposed from the outside.

Halverson (2004), says that the simplistic strategy of directly teaching ethics does not work. (Robert Coles The Moral Life of Children 1986), speaks to this same misinterpretation. It is a mistake to think of morality as a set of external standards that adults somehow foist upon an unknowing or unwilling child...most of our current moral education efforts fail precisely because of this mistaken yet pervasive assumption. (Alfie Kohn 1997), offers a similarly critical assessment of character education in schools. He feels that character education in most schools is a form of indoctrination in which absolutes of moral action are instilled or transmitted. According to (Gibbs 1991), who works specifically with antisocial adolescents reports processes similar to those found by Bandura. Gibbs held discussions with youth involved in juvenile justice systems.

According to (Piaget 1965), children construct and reconstruct their knowledge of the world through 
interactions with the environment. Being a good person involves more than the cognitive understanding of what is right and what is wrong. Other central aspects of moral functioning include empathy, conscience, and altruism (Berkowitz \& Grych 1998). There are several studies that indicate that the self-reported use of inductive discipline authoritative parenting affection support responsiveness and involvement has been associated with youth's moral maturity (Hoffman \& Saltzstein 1967; Parikh 1980; Hart 1988; Speicher, 1992; Boyes \& Allen 1993).

Similarly, behavioral ratings of parenting style have revealed that parental responsiveness and psychological differentiation are related to youth's moral development (Holstein, 1972; Parikh, 1980); Dunton, (1989). Doubtfully attached youth are likely to distance themselves from their parents either by ceasing religious attendance or by joining a different religious organization and seeking attachment and family there (Kirkpatrick \& Shaver 1990). Religious organizations that successfully foster youth involvement offer youth-oriented contexts of spiritual development, but also provide youth with a role in the larger religious community that is consistent with their almost-adult status (Ream \& Witt 2003).

\section{Theoretical Understanding:}

Many theories have been used in previous studies to analyze moral behavior among youths. In our research, social development theories and Behaviorist theory have been used to analyze moral behavior among the youths.

\subsection{Social Developmental Theories:}

The social developmental theory has been used to measure the relationships between social and environmental factors and their influence on youth's behavior and personality. It emphasizes the behavioral component of morality. An example of social development theory is Bandura's social learning theory. Social learning theory was postulated by (Bandura 1925) who regards human beings as agents of their own lives. It takes into reflection role of the influence of the surrounding of role models, self-efficacy, beliefs, and perceptions. According to (Nkwopara 2011), Bandura was interested in the behavioral component of morality which is part of this study. Moral behavior is strongly influenced by the nature of the specific situation in which people find themselves. This theory emphasizes that behavior is a result of the interaction of personal factors and the environment, predirecting the person to act in a certain way. Bandura believes that most human learning is observational learning, not conditioning, and occurs by observing others.

\subsection{Behaviorist Theory:}

The behaviorist attempts to explain moral behavior through the process of strengthening, conditioning, imitation, and modeling (Alfrey 2010), Skinner's radical behaviorism theory proposed that moral behavior is learned in the course of human development through association, imitation, practice, and reinforcement. (Skinner 1971:p95) argues that one's behavior can form and prohibited that conforms in all proceedings to what is best for the survival of the culture. It is a basic philosophic disagreement of radical behaviorism that all behavior is unwavering and under the control of environmental factors. (Skinner 1971:p102) believes that equipment is good which make stronger or compensation the individual. Those things are bad which do not strengthen or reward the individual.

\section{Methodology of the Study:}

The research design of the study was descriptive in nature of the study. The study focuses on discovering the role of the family in the influence of youth's moral behavior in Bangladesh. The study area was both Dhaka city corporations. The study requires both primary and secondary data. Secondary data were collected from different books, journals, articles, government reports, websites, previous research reports, etc. while primary data were collected from parents by using survey method. The sample size for the study consisted of 200 parents who were randomly selected from the sampled schools from both Dhaka city corporation areas as presented in table-1 the selection of sample size was done through the simple random sampling technique. The main purpose of using a simple random sampling technique was to complete a sample that could be generalized to a bigger population.

\begin{tabular}{|l|c|c|c|c|c|c|}
\hline Distribution of Sample Size \\
\hline Communities & Families & Housewife & Service Holder & Male & Female & Total \\
\hline Dhaka North & 116 & 64 & 52 & 28 & 88 & $\mathbf{1 1 6}$ \\
\hline Dhaka South & 84 & 47 & 41 & 22 & 62 & $\mathbf{8 4}$ \\
\hline Total & $\mathbf{2 0 0}$ & $\mathbf{1 1 1}$ & $\mathbf{8 9}$ & $\mathbf{5 0}$ & $\mathbf{1 5 0}$ & $\mathbf{2 0 0}$ \\
\hline
\end{tabular}

Source: Field Survey, 2021

The instrument used for data collection was a structured questionnaire for an easy way of determining information from the selected respondents (Parents). The questionnaire was designed according to the Likert Scale for each item required for the respondent to answer various acts under Strongly Agreed (SA), Agreed (A), Disagreed (D), and Strongly Disagree (SD) was adopted for the responses on the questionnaire. The survey and 
interview data were processed with the use of Statistical Package for the Social Science (SPSS). All qualitative data were also analyzed prior to considering the objectives of the study. Mean and the Standard deviation was used to answer research questions 1, 2, 3, and 4. Hypothesis 1 and 2 were tested using simple chi-square (x2). The null hypothesis was tested at a 0.05 level of significance for interpreting the results of the analysis for the research questions $1,2,3$, and 4are mean value of 2.50 and above was accepted while a mean value below 2.50 was rejected. For hypotheses 1 and 2, if $t$-calculated is greater than t-critical, the hypothesis is rejected and if $t-$ calculated is less then t-critical is accepted.

\section{Findings and Result Analysis:}

5.1. How does the socio-economic background affect the influence of moral behaviors in youths within families in Dhaka both city corporations?

\begin{tabular}{|l|l|l|l|l|}
\hline Item no & Peer influence on youth moral behavior & $\mathbf{X}$ & Std. & Decision \\
\hline 1 & $\begin{array}{l}\text { Youths are lack self-confidence and socially introverted because of their } \\
\text { friends. }\end{array}$ & 2.52 & 1.13 & Accepted \\
\hline 2 & Youths can't break down bad habits because of their friends. & 2.74 & 1.07 & Accepted \\
\hline 3 & $\begin{array}{l}\text { Friends can influence you to follow their beliefs from their own eyes and } \\
\text { convince you that it is reality. }\end{array}$ & 3.10 & 0.79 & Accepted \\
\hline 4 & $\begin{array}{l}\text { Humans are particularly receptive to suggestions, especially from close } \\
\text { friends. }\end{array}$ & 2.56 & 0.97 & Accepted \\
\hline 5 & A peer can help motivate youths to face challenges. & 3.08 & 0.79 & Accepted \\
\hline 6 & $\begin{array}{l}\text { Peer pressure inspirations youths choice to keep } \\
\text { Friends (boyfriend or girlfriend). }\end{array}$ & 2.78 & 1.09 & Accepted \\
\hline 7 & Peer influence affects youths' behavioral patterns. & 2.92 & 1.19 & Accepted \\
\hline 8 & Peer influences our choice of fashion. & 2.72 & 1.00 & Accepted \\
\hline 9 & Peer influence exposes us to smoking (alcohol and drug use). & 3.01 & 0.79 & Accepted \\
\hline 10 & The peer can influence our choice of religion. & 2.36 & 0.95 & Rejected \\
\hline
\end{tabular}

$$
\text { Grand mean }=2.77
$$

Here the research question one (Table 5.1) shows that items 1, 2, 3, 4, 5, 6, 7, 8, and 9 were accepted based on the judgment rule while item 10, is rejected. Since the accepted items are more than the rejected item. The grand mean is 2.77 which shows acceptability on the decision rule. We, therefore, accept that peer influence is a factor that affects the moral behavior of youths within families.

5.2. How do mass media and modern technology influence of moral behavior in youths within the families in Dhaka both city corporations?

\begin{tabular}{|c|c|c|c|c|}
\hline Item no & Mass Media \&Modern Technology & $\mathbf{X}$ & Std. & Decision \\
\hline 11 & $\begin{array}{l}\text { Online video games show violent acts contribute to the aggressive } \\
\text { behavior of youths. }\end{array}$ & 2.80 & 1.02 & Accepted \\
\hline 12 & $\begin{array}{l}\text { Televisions help youths to learn about other own cultures, norms, } \\
\text { values and ethics. }\end{array}$ & 2.80 & 1.00 & Accepted \\
\hline 13 & Mass media \& technology helps youths in an anti-drug campaign & 2.52 & 1.28 & Accepted \\
\hline 14 & $\begin{array}{l}\text { Actor's immoral behaviors on the TV screen encourage youth's } \\
\text { immorality. }\end{array}$ & 2.92 & 1.11 & Accepted \\
\hline 15 & $\begin{array}{l}\text { Technology such as social networking distracts the youths from } \\
\text { their self-responsibilities in the family. }\end{array}$ & 2.95 & 1.09 & Accepted \\
\hline 16 & $\begin{array}{l}\text { Technology provides youth access to pornographic pictures and } \\
\text { movies to destroy morality. }\end{array}$ & 2.92 & 1.27 & Accepted \\
\hline 17 & $\begin{array}{l}\text { Technology provides youths the opportunity to access moral articles } \\
\text { online. }\end{array}$ & 2.24 & 1.14 & Rejected \\
\hline
\end{tabular}

Grand mean $=2.27$

Here the research question two (Table 5.2) shows that items 11, 12,13,14,15, and 16 are accepted based on the judgment rule while item 17 is rejected. Here the mean below is 2.50 . It shows that mass media and modern technology is a factor that effects moral behavior in youth within families. Hence mass media and modern technology scored the grand mean of 2.76 which implies its acceptability as a factor that affects the moral behavior in youths within families. 
5.3. How do the social and family environmental factors affect on moral behaviors of youth's psychology within the families in Dhaka both city corporations?

\begin{tabular}{|c|c|c|c|c|}
\hline Item no & Social and Families Environmental Factor & $\mathbf{X}$ & Std. & Decision \\
\hline 18 & $\begin{array}{l}\text { Social and families environmental factors can influence youths' } \\
\text { choice of role model. }\end{array}$ & 2.76 & 0.94 & Accepted \\
\hline 19 & The social environment can influence youth's mode of dressing. & 2.68 & 1.02 & Accepted \\
\hline 20 & Family violence can affect youths' behavioral patterns. & 2.68 & 1.09 & Accepted \\
\hline 21 & Family environment influences the way we relate with others & 2.00 & 0.9 & Rejected \\
\hline 22 & Family environment can influence youth's belief system. & 2.88 & 0.96 & Accepted \\
\hline 23 & $\begin{array}{l}\text { Modern culture and social environment illicit market and exposure } \\
\text { to the social organization of criminal activity esc an worsen } \\
\text { immoral behavior among the youths. }\end{array}$ & 2.64 & 1.36 & Accepted \\
\hline 24 & $\begin{array}{l}\text { A bad family environment can lead to easy access to illegal drugs } \\
\text { and guns. }\end{array}$ & 2.64 & 1.36 & Accepted \\
\hline 25 & $\begin{array}{l}\text { Divorce, dowry and domestic violence increasing the number of } \\
\text { single parents can influence the moral behavior of youths. }\end{array}$ & 2.54 & 0.90 & Accepted \\
\hline 26 & $\begin{array}{l}\text { Corrupted leaders and social systems influence youths' illegal and } \\
\text { anti-social activities. }\end{array}$ & 2.72 & 1.16 & Accepted \\
\hline
\end{tabular}

Grand mean $=2.64$

Here the research question three (Table 5.3) shows that items 18,19,20,22,23,24,25 and 26 were accepted based on the judgment rule while item 21 was rejected on the decision rule as it scored the mean rating below 2.50. Since the accepted items are more than the rejected item in table 3, this, therefore, implies that environmental factor effect of moral behavior in youths within families.

5.4. How do peer groups influence and role model the effect of moral behavior of youths within the families in Dhaka both city corporations?

\begin{tabular}{|l|l|l|l|l|}
\hline Item no & Socio-economic Status & X & Std. & Decision \\
\hline 27 & $\begin{array}{l}\text { Lower socioeconomic status increases the high rate of attempted suicides, } \\
\text { smoking, and engaging in episodic heavy drinking. }\end{array}$ & 3.22 & 0.81 & Accepted \\
\hline 28 & $\begin{array}{l}\text { Lower SES can lead to a high level of emotional behavior difficulties } \\
\text { including anxiety, depression, and mental disorder in youths. }\end{array}$ & 2.76 & 1.06 & Accepted \\
\hline 29 & Lower SES can lead to a high level of aggression and anger in youths. & 2.92 & 0.95 & Accepted \\
\hline 30 & Lower SES can lead to high victims of violence among family members. & 2.40 & 0.14 & Rejected \\
\hline 31 & $\begin{array}{l}\text { Lower SES can influence the lower level of moral behavior and education } \\
\text { in youths. }\end{array}$ & 2.94 & 0.89 & Accepted \\
\hline 32 & $\begin{array}{l}\text { Higher SES can helps to build rigorous personality in youth } \\
\text { The family SES can influence the behavioral pattern of youths within the } \\
\text { family. }\end{array}$ & 2.79 & 0.89 & Accepted \\
\hline 33
\end{tabular}

Grand mean $=2.87$

Here the research question four (Table 5.4) shows that items 27, 28, 29, 31, 32, and 33 were accepted on the decision rule while item 30 was rejected as it scored the mean rating below 2.50. Since the accepted level is more than the rejected item in table 4, this implies that the socio-economic status of the family affects the inculcation of moral behavior in youths within families.

\subsection{Hypothesis Testing:}

Ho1: There is no significant difference between housewife and service holder urban families on how socioeconomic factors affect the moral behavior in youths within the families.

Table 5.5 Mean response in housewife and service holder urban families on how socio-psychological factors affect moral behavior in youths within the families.

\begin{tabular}{llllllll}
\hline Status & $\mathbf{N}$ & $\mathbf{X}$ & Std. & DF & T-cal & T-table & Decision \\
\hline Housewife & 111 & 3.25 & 0.81 & & & & \\
Service holder & 89 & 2.89 & 1.40 & & & & Rejected \\
Total & $\mathbf{2 0 0}$ & & & $\mathbf{3}$ & $\mathbf{1 4 . 3 8}$ & $\mathbf{7 . 8 1}$ & \\
\hline
\end{tabular}

Decision Rule: Here accept the null hypothesis when $\mathrm{x} 2$-calc. is less than $\mathrm{x} 2$-tab, that is $(\mathrm{x} 2-\mathrm{cal}<\mathrm{x} 2-\mathrm{tab})$ and rejected when $\mathrm{x} 2$-cal is greater than 2 2-tab, that is $(\mathrm{x} 2-\mathrm{cal}>\mathrm{x} 2-\mathrm{tab})$. From the table above the calculated chisquare is greater than the tabulated chi-square, we, therefore, reject the null hypothesis and accept the alternative hypothesis that there is a significant difference in the mean responses of the housewife and service holder urban families on how socio-psychological factors affect the moral behavior in youths within the families on both 
Dhaka city corporations in Bangladesh.

Ho2: There is no significant difference between the mean responses of males and females on peer group influence of moral behaviors in youths within the families.

Table-5.6 there is no significant difference between the mean responses of males and females on peer group influence of moral behaviors in youths within the families.

\begin{tabular}{cccccccc}
\hline Status & $\mathbf{N}$ & $\mathbf{X}$ & Std. & $\mathbf{D F}$ & T-cal & T-table & Decision \\
\hline Male & 50 & 2.05 & 0.73 & & & & \\
Female & 150 & 3.49 & 1.24 & & & & \\
Total & $\mathbf{2 0 0}$ & & & $\mathbf{3}$ & $\mathbf{6 . 9 6}$ & $\mathbf{7 . 8 1}$ & Accepted \\
\hline
\end{tabular}

Decision Rule: Here accept the null hypothesis when the $\mathrm{x} 2$-cal is less than the $\mathrm{x} 2$-tab that is $(\mathrm{x} 2-\mathrm{cal}<\mathrm{x} 2-$ $\mathrm{tab})$ and reject when the $\mathrm{x} 2$-calculation value is greater than the $\mathrm{x} 2$-table value that is $(\mathrm{x} 2-\mathrm{cal}>\mathrm{x} 2-\mathrm{tab}$. In the chisquare table above, the calculated chi-square is less than the tabulated chi-square, we then accept the null hypothesis that there is no significant difference between the response of male and female on how peer influence affect moral behavior in youths within families on both Dhaka city corporations in Bangladesh.

\section{General Discussions:}

The result of data analyses in table one discovered that peer influence effects ofmoral behavior in youth within families as it scored mean above 2.50. The findings of this study are in concurrence with (Olaitan, Mohmed, and Ajibola, 2013), that peer influence can lead to regulation problems and youth antisocial activities both inside and outside the school. Also, (Radwan 2015), showed that everyone wants to be accepted and loved most teens try to conform to the group they belong to by wearing similar clothes and adopting similar behavior. The result of data analysis in table 2 discovered that modern technology affects moral behavior in youth within the families. Hence, youths, access to modern technology should be supervised and made sure with (Barrell and Fic 2013), when they found that one of the most important advantages of modern technology is globalization. This has allowed the world to feel closer and tolerable the world's economy to become a single interdependent system. Where people can not only share information quickly and efficiently bring down barriers of linguistic and geographic borders. (Davies and Eynon 2013), argued that youths in today's world mobile phones, the internet, music, movies, television, and video games are very important. Most teenagers prefer watching television and playing computer games to reading books. They dislike reading because watching television or playing online games is easier and they do not have to use their own imagination. (Longo 2010), argued that computer games have the capacity to provide a teaching opportunity but they are also harmful to health. The result of data analysis in table 3 exposed socio-psychological environments affects the moral behavior of youths within families in both city corporation area. This is supported by (Obiefuna 2010), argued that human beings are products of their socio-psychological environment in terms of the interaction that exists between the individual and the society. However, (Gainey 2013), argued that delinquency is a class-specific behavior. As a result, social bonding, class consciousness, alienation, and negative labeling are the peacekeepers on the relationship between family SES and delinquent behavior. The data analysis in table 4, observed that there were differences in their views on how socioeconomic factor affects the moral behavior of youths within families. The data analysis of table 5 showed that there was no significant difference between the mean rating of the male and female on how peer influences affect the inculcation of moral behavior in youths within the families.

\section{Findings of the Study:}

This research result analysis major significant findings are given below;

$\checkmark$ Peer influence of moral behavior in youths within the families, where the majority of youths have a lack of self-confidence. As a result, youths are highly influenced by peer behavior.

$\checkmark$ Modern technology affects moral behavior, whereas online video games show violent acts contribute to the aggressive behavior of youths. Thus, encouraging immorality.

$\checkmark \quad$ Social and family environment affects moral behaviors in youths within families, where the social and family environment can influence youths' choice of role model, one's mode of dressing, behavioral pattern and corrupt leaders and social system influence of youth's illegal and anti-social activities.

$\checkmark$ Socio-economic factors affect moral behavior in youths within families, where low socioeconomic status increases the high rate of attempted suicides, smoking, and drinking.

\section{Recommendations}

There are some policy recommendations for further improvement of youth's moral behavior within the family and out of the family. Those are given below;

$>$ Parents should be providing proper and sufficient home training for our youths. Religious norms and values are also taught by the families.

$>$ Parents should concern about the social and cultural environment of socialization to raise their children 
as surroundings have great influences on the moral behavior of children and youths.

$>$ Youth's access to modern technology and social networking site should be properly monitored to avoid being exposed to pornography addiction and immoralities.

$>$ It would be a cry-off in the feat among the students and the society in general if the factor affecting the moral behavior in youths is not checked.

$>$ The study discovered that moral dissipation can generate hostile and unbearable teaching and learning environment if these factors responsible for moral behavior in youths.

\section{Conclusions:}

This research finding has shown that the moral character of youths is declining rapidly due to the moral behavioral standard of youths in our society. They are more desperate and crazy it is alarming to future generations and social systems. Considering the dimension of violent and moral misconduct in our society today, like jongibad and terrorism issues also Islamic religious extremism, armed robbers, kidnapping cases, juvenile delinquency, etc. But remedies to those factors that cause moral misconduct in our society. On the other hand, the findings of this study showed that youths have more tendency of being morally self-indulgent as these factors expose them to high dangers today. So every angle of society parents and civil society must be knocking over in checking immoralities in youths at schools, families, and nations. Thus there is a dire need to check these factors that affect moral behavior in youths to ensure a positive outcome for future generations.

\section{References}

Alfrey, C. (2010). Juvenile Delinquency \& family Structure: Implications for marriage and relationship education. Retrieved April 20th, 2010 fromhttp://www.healthymarriageinfo.org/docs/juveniledelinquency.pdf

Anasi, S.N.I (2010). Curbing youth restiveness in Nigeria: The role of information and libraries Retrieved 24.10.2012 from http://digitalcommons.uni.edu/cgi/viewcontent.cgi? Article1404.

Asim, O. N (2004), Psychology of adjustment and career development for all educational levels. Enugu: Unizik Press Limited.

Bandura, A.(1925). Key theories in psychology: psychology resource site. Available at www.psy.palx.edu.keytheorist.accessedon 06/05/2009.

Barrell, R. \& Fic, T. (2013), Integration, globalization, technology, and trade patterns in the EU8.Research in Economics and Business: Central and Eastern Europe, 2(1), 1-13.

Bennett, S. \& Maton, K. (2010), beyond the digital natives' Journal of Computer Assisted Learning, 26(5), 321331

Berkowitch, M.W., \&Grych, J.H. (1998), Fostering goodness: teaching parents to facilitate children's moral development. Journal of Moral Education, 27(3), 371- 391.

Boyes, M.C. \& Allen, S.G. (1993) Styles of parent-child interaction and moral reasoning in adolescence, MerrillPalmer Quarterly, 39,551-570.

Callahan, D. (2004). The cheating culture: why more Americans are doing wrong to get ahead. Orlando: Harcourt.

Coeckelbergh, M. (2012). How I learned to love the robot Capabilities, information technologies, and elderly care. Springer, 77-86.

Coles, R. (1986). The moral life of children. Berkeley: Publishers Group West.

Davies, C. \& Eynon, R. (2013).Teenagers and technology. Hove: Routledge.

Defoe, I. N., (2013). Disentangling the Relationship between Delinquency and Hyperactivity, Journal of Criminal Justice 41(1), 100-107.

Dunton, K.J. (1989) Parenting practices associated with their children's moral reasoning development, Dissertation Abstracts International, 49, p. 3306A (University Microlms no. 8826133).

Gainey, K. (2013). Evaluation of the model to the prediction of anxiety and mood disorder constructs behavior therapy, 44(1), 277-292.

Gibbs, J. C. (1991). Socio-moral developmental delay and cognitive distortions: Implications for the treatment of antisocial youth.

Griswold, W. (2012).Cultures and societies in a changing world (4thedn). Thousand Oaks, CA: SAGE.

Haidt, J. (2012). the righteous mind: why good people are divided by politics and religion. Pantheon Books, New York, NY.

Halverson, S (2004). Teaching ethics: the role of the classroom teacher. Childhood Education, 80(3), 157.

Hart, D. (1988) A longitudinal study of adolescents' socialization and identification as predictors of adult moral judgment development, Merrill-Palmer Quarterly, 34,245 to 260.

Hart, D., \& Atkins, R. (2002). Civic development in urban youth. Applied Developmental Science, 6, $227-236$.

Hart, D., Atkins, R., Markey, P., \&Youniss, J. (2004). Youth bulges in communities: The effects of age structure 
on adolescent civic knowledge and civic participation. Psychological Science, 15,591-597.

Hoffman, M.L. \& Saltzstein, H.A. (1967). Parent discipline and the child's moral development, Journal of Personality and Social Psychology, 5, 45-57.

Holstein, C.B. (1972) the relation of children's moral judgment level to that of their parents and to communication patterns in the family, Readings in Child Development and Relationships, 484 to 494 (New York, Macmillan).

Kirkpatrick,L.A.,\&Shaver, P. R. (1990). Attachment theory and religion: Childhood attachments, religious beliefs, and conversion. Journal for the Scientific Study of Religion, 29(3), 315-334.

Ream, G. L., \& Witt, P. A. (2003). Organizations serving all ages. In S. F. Hamilton \& M. A. Hamilton (Eds.), Handbook of Youth Development (pp. 49-74). Thousand Oaks, CA: Sage.

Kohlberg, L. (1984). The psychology of moral development. New York: Harper \& Row.

Kohn, A. (1997). How not to teach values. Education Digest, 62(9), 12.

Kwak, A. (2005). Rodzina w dobieprzemian. Małżeństwoikohabitacja. Warszawa.

Longo, G.O. (2010). Communication, technology, and the planetary creature. Communication, Capitalism \& Critique, 8(1), 18-27.

Nkwopara, C. (2011, March, 1). Drug barons convert government farms into Indian hemp farms. Daily Vanguard, 36-37.

Obiefuna, B. A. C. (2010). Moral decadence among the youth in Nigeria: lessons from part the apodle. African Journal of Local Society Initiative.

Olaitan, S. O., Mohmed \& Ajibola (2013). The making of a curriculum: theory, process and evaluation. Onitsha: Cape publisher international ltd.

Omede, J. \&Odiba, P. (2010). Youths Restiveness Across the globe: where the adults may have gone wrong. In J. Omede (Ed).Higher education and Global Challenges. Ankpa: ROMA computers.

Parikh, B. (1980) Development of moral judgment and its relation to family environmental factors in Indian and American families, Child Development, 51, 1030-1039.

Piaget, J. (1965). The moral judgment of the child. New York: The Free Press.

Radwan, N.D (2015). Hollywood Movies and Nigerian Youths. An evaluation. JORIND 10 (2).

Skinner, B. F. (1971). Beyond freedom and dignity. New York: Knopf.

Speicher, B. (1992) Adolescent moral judgment and perceptions of family interaction, Journal of Family Psychology, 6,128-38. 